\title{
MINIMALLY INVASIVE VERSUS STERNOTOMY APPROACHES FOR MITRAL RECONSTRUCTION: COMPARISON OF INTERMEDIATE-TERM RESULTS
}

\author{
Eugene A. Grossi, MD \\ Angelo LaPietra, MD \\ Greg H. Ribakove, MD \\ Julie Delianides, MA \\ Rick Esposito, MD \\ Alfred T. Culliford, MD \\ Christopher C. Derivaux, MD \\ Robert M. Applebaum, MD \\ Itzhak Kronzon, MD \\ Bryan M. Steinberg, MD \\ F. Gregory Baumann, PhD \\ Aubrey C. Galloway, MD \\ Stephen B. Colvin, MD
}

Background: This study compares intermediate-term outcomes of mitral valve reconstruction after either the standard sternotomy approach or the new minimally invasive approach. Although minimally invasive mitral valve operations appear to offer certain advantages, such as reduced postoperative discomfort and decreased postoperative recovery time, the intermediate-term functional and echocardiographic efficacy has not yet been documented.

Methods: From May 1996 to February 1999, 100 consecutive patients underwent primary mitral reconstruction through a minimally invasive right anterior thoracotomy and peripheral cardiopulmonary bypass and Port-Access technology (Heartport, Inc, Redwood City, Calif). Outcomes were compared with those for our previous 100 patients undergoing primary mitral repair who were operated on with the standard sternotomy approach.

Results: Although patients were similar in age, the patients undergoing the minimally invasive approach had a lower preoperative New York Heart Association classification $(2.1 \pm 0.5$ vs $2.6 \pm 0.6, P<.001)$. There was one $(1.0 \%)$ hospital mortality with the sternotomy approach and no such case with the minimally invasive approach. Follow-up revealed that residual mitral insufficiency was similar between the minimally invasive and sternotomy approaches $(0.79 \pm 0.06$ vs $0.77 \pm 0.06, P=.89,0$ - to 3 -point scale $)$; likewise, the cumulative freedom from reoperation was not significantly different $(94.4 \%$ vs $96.8 \%, P=.38)$. Follow-up New York Heart Association functional class was significantly better in the patients undergoing the minimally invasive approach $(1.5 \pm 0.05$ vs $1.2 \pm 0.05, P<.01)$.

Conclusions: These findings demonstrate comparable 1-year follow-up results after minimally invasive mitral valve reconstruction. Both echocardiographic results and New York Heart Association functional improvements were compatible with results achieved with the standard sternotomy approach. The minimally invasive approach for mitral valve reconstruction provides equally durable results with marked advantages for the patient and should be more widely adopted. (J Thorac Cardiovasc Surg 2001;121:708-13)
A dvances in minimally invasive approaches for cardiac operations have been achieved in the last several years. The development of new techniques and cannula systems has allowed surgeons to place bypass grafts on the heart and perform valvular heart opera-

From the Divisions of Cardiothoracic Surgery and Cardiology, New York University School of Medicine, New York, NY.

Supported in part by The Foundation for Research in Cardiac Surgery and Cardiovascular Biology.

Copyright (C) 2001 by The American Association for Thoracic Surgery

$0022-5223 / 2001 \$ 35.00+0 \quad \mathbf{1 2 / 1 / 1 1 2 6 2 6}$

doi: $10.1067 / \mathrm{mtc} .2001 .112626$ tions without the need for the traditional sternotomy incision. ${ }^{1-3}$ The quest for minimizing the surgical incisions necessary for these procedures has been fueled by many disparate factors, including enhanced patient outcome, speedier patient recovery, less trauma, and better cosmesis. ${ }^{4}$ Although several studies have documented the perioperative outcomes of a minimally invasive approach, ${ }^{5-7}$ it is unknown whether the longer term outcome of a complex valvular operation, such as mitral reconstruction, would be compromised or unaffected by this newer surgical approach. This report documents a single institution's initial experience with minimally invasive mitral reconstruction, with intermediate-term clinical and echocardiographic follow-up. 


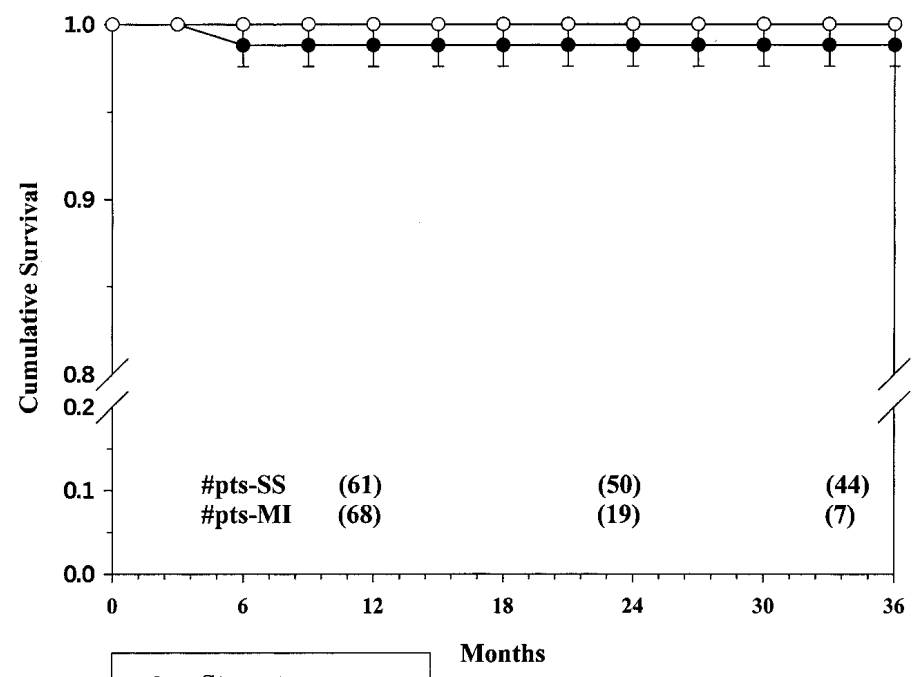

\section{A}

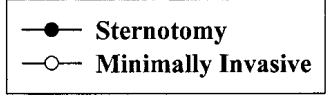

Wilcoxon statistic: $\mathbf{p}=\mathbf{0 . 3 0}$

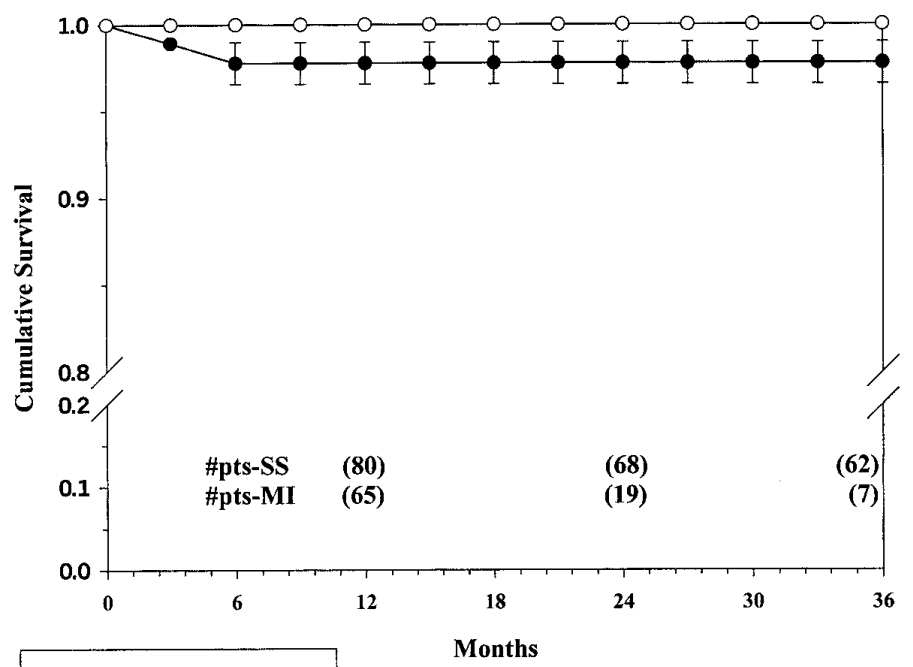

B

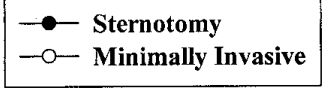

Wilcoxon statistic: $\mathbf{p}=\mathbf{0 . 3 0}$

Fig 1. A, Cumulative survival from late cardiac death. B, Cumulative survival from all late death. SS, Standard sternotomy approach; $M I$, minimally invasive approach.

\section{Methods}

From May 1996 through February 1999, 100 consecutive patients at our institution underwent primary mitral valve reconstruction with ring annuloplasty for severe mitral insufficiency through the Port-Access minimally invasive technique (Heartport, Inc, Redwood City, Calif). ${ }^{8}$ Primary mitral valve reconstruction means the patients had no prior cardiac operations, and the operative procedure was an isolated mitral valve reconstruction (excluded are concomitant coronary artery bypass grafting and multiple valve operations). During this time interval, this procedure included peripheral cardiopulmonary bypass, percutaneous coronary sinus cardio- plegia, and endovascular aortic balloon occlusion. A small right anterior thoracotomy was performed for access to the mitral valve. Standard mitral reconstructive techniques, including ring annuloplasty, were performed and have been described previously. ${ }^{9,10}$ The last 100 consecutive patients undergoing sternotomy approach primary mitral valve reconstruction at our institution were identified as the control population (September 1993-November 1999). This homogeneous patient population was examined to identify the effect of technique on short- and long-term outcome. Eleven of these patients undergoing the sternotomy approach were operated on after the commercial release of the minimally 
Table I. Patient clinical characteristics and comparison between the minimally invasive and standard sternotomy approaches for isolated mitral valve reconstruction

\begin{tabular}{lccc}
\hline & $S S(n=100)$ & MI $(n=100)$ & P value \\
\hline Age (y) & $55.3 \pm 17.2$ & $56.2 \pm 13.6$ & .70 \\
Preoperative NYHA & $2.60 \pm 0.60$ & $2.10 \pm 0.50$ & $<.001$ \\
Bypass time (min) & $128 \pm 46.0$ & $135.3 \pm 25.9$ & .18 \\
Sex, \% male & $55 \%(55 / 100)$ & $71 \%(71 / 100)$ & .02 \\
Ejection fraction & $52.9 \pm 15.3$ & $55.9 \pm 10.7$ & .13 \\
Pulmonary systolic pressure (mm Hg) & $41.7 \pm 19.4$ & $36.2 \pm 14.9$ & .04 \\
Diabetes mellitus & $5 \%(5 / 100)$ & $3 \%(3 / 100)$ & .47 \\
Hospital mortality & $1.0 \%(1)$ & $0.0 \%(0)$ & .32 \\
Permanent neurologic deficit & $1.0 \%(1)$ & $2.0 \%(2)$ & .64 \\
Without major hospital morbidity* & $88 \%(88)$ & $91 \%(91)$ & .49 \\
Residual mitral insufficiency at 1 y $\dagger$ & $0.79 \pm 0.06$ & $0.77 \pm 0.06$ & .89 \\
NYHA 1-y postoperatively & $1.5 \pm 0.05$ & $1.24 \pm 0.05$ & $<.01$ \\
Freedom from reoperation at 1 y & $94.4 \%$ & $96.8 \%$ & .38 \\
\hline
\end{tabular}

Results are given as mean \pm SD where shown. SS, Standard sternotomy approach; $M I$, minimally invasive approach.

*Morbidity is defined by New York State Adult Cardiac Surgery Report Form major hospital morbidity, including stroke, transmural myocardial infarction, deep sternal wound infection, bleeding requiring reoperation, sepsis or endocarditis, gastrointestinal bleeding, perforation or infarction, renal failure, dialysis, or respiratory failure.

$\dagger$ Echocardiographic scale: 0, none; 1, mild; 2, moderate; 3, severe.

Table II. Incidence of pathophysiology of mitral insufficiency categorized by surgical approach

\begin{tabular}{lcrr}
\hline & $\begin{array}{c}\text { SS } \\
(n=100)\end{array}$ & $\begin{array}{c}\text { MI } \\
(n=100)\end{array}$ & P value \\
\hline Cause of valvular insufficiency & & & .01 \\
$\quad$ Degenerative & $72.0 \%$ & $92.0 \%$ & \\
Rheumatic & $10.0 \%$ & $2.0 \%$ & \\
Ischemic & $1.0 \%$ & $1.0 \%$ & \\
Infectious & $7.0 \%$ & $2.0 \%$ & \\
Other & $10.0 \%$ & $3.0 \%$ & \\
\hline
\end{tabular}

$S S$, Standard sternotomy approach; $M I$, minimally invasive approach.

invasive equipment by surgeons performing the minimally invasive approach. These patients will be discussed subsequently.

Operative information and patient demographics for patients undergoing mitral valve reconstruction are routinely collected at our institution. Hospital morbidity was tabulated by using the types of operative complications listed on the New York State Adult Cardiac Surgery Report Form. Clinical research nurses maintain biannual contact with the patients and record follow-up information, including clinical status and echocardiographic studies. Echocardiography was used to evaluate mitral insufficiency on a 3-point scale as none (0), mild (1), moderate (2), or severe (3). A total of 425 years of patient follow-up was reviewed in this report (mean 33 months). The statistical software program SPSS (SPSS, Inc, Chicago, Ill) was used to analyze the data. $\chi^{2}$ Analysis was used for categoric variables, and the $t$ test was used for continuous variables. Survival analysis was performed by using life table methodology; differences were tested with a Wilcoxon statistic. Actual or cumulative incidence analysis was performed for analysis of complications. ${ }^{11,12}$
Table III. Incidence of operative technique for mitral repair categorized by surgical approach

\begin{tabular}{lccc}
\hline & $\begin{array}{c}S S \\
(n=100)\end{array}$ & $\begin{array}{c}\text { MI } \\
(n=100)\end{array}$ & $\mathrm{P}$ value \\
\hline Posterior leaflet resection & $80.0 \%$ & $81.0 \%$ & .85 \\
Anterior leaflet resection & $32.0 \%$ & $39.0 \%$ & .30 \\
\hline
\end{tabular}

SS, Standard sternotomy approach; $M I$, minimally invasive approach.

\section{Results}

Table I compares patient demographics between the 2 surgical approaches. Although the patient ages and pulmonary artery pressures were similar, the preoperative New York Heart Association (NYHA) functional classification was worse in the group undergoing the sternotomy approach $(2.6 \pm 0.6$ vs $2.1 \pm 0.5, P<.001)$. The patients undergoing the minimally invasive approach had a higher incidence of degenerative cause and a lower incidence of rheumatic cause for the valvular disease (Table II). The average cardiopulmonary bypass time was 7 minutes longer with the minimally invasive approach $(135.3 \pm 25.9$ vs $128.0 \pm 46.0 \mathrm{~min}$ utes, $P=.18$ ). Similar numbers of anterior and posterior leaflet procedures were performed in each group (Table III). The hospital mortality was $1.0 \%$ for the sternotomy and $0.0 \%$ for the minimally invasive approach. Permanent neurologic perioperative events occurred in $1.0 \%$ of patients undergoing sternotomy and $2.0 \%$ of the patients undergoing the minimally invasive approach. No aortic dissections or injury occurred in either patient group. Freedom from any 


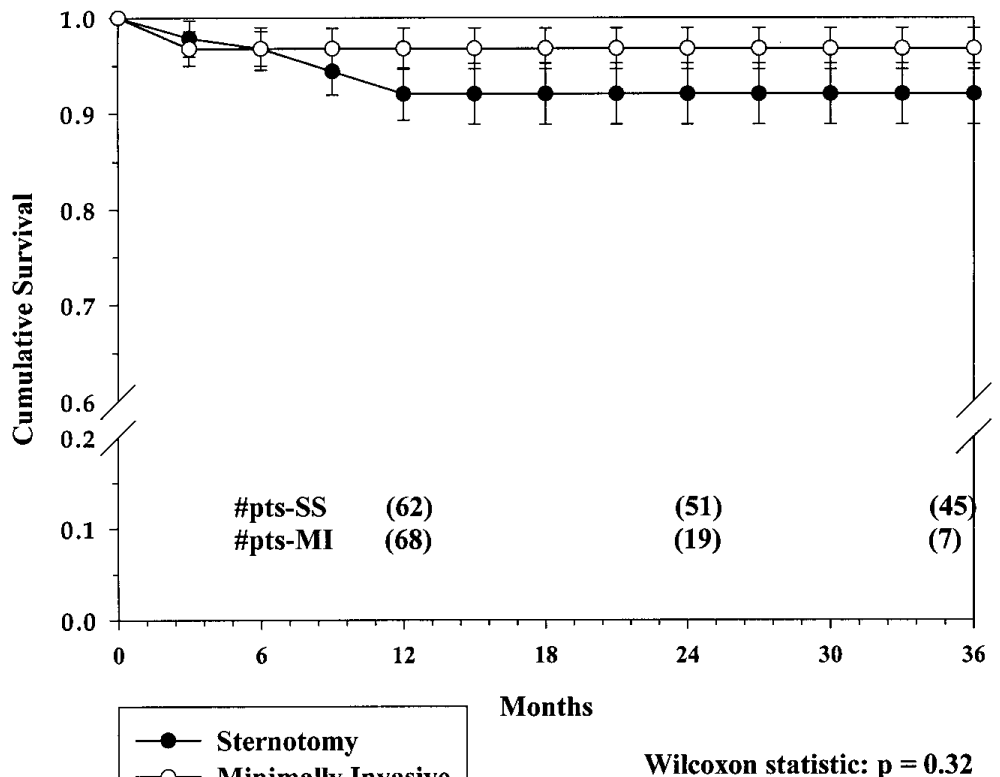

Fig 2. Cumulative survival from mitral reoperation of any cause. SS, Standard sternotomy approach; MI, minimally invasive approach.

hospital morbidity was $88 \%$ for the sternotomy approach group and $91 \%$ for the minimally invasive approach group $(P=.49)$.

Fig $1, A$ and $B$, respectively, depict the cumulative survival curves from freedom from late cardiac death and all death. At 1 year of follow-up, residual mitral insufficiency was similar between the sternotomy and minimally invasive approach groups $(0.79 \pm 0.06$ vs $0.77 \pm 0.06, P=.89,0-3$ scale), and likewise, the actual freedom from reoperation was similar $(94.4 \%$ vs $96.8 \%, P=.38$ ) at 1 year (Fig 2). Indications for reoperation within the first year are listed in Table IV. NYHA functional classification at follow-up was different, with the patients in the minimally invasive approach group being less symptomatic (1.2 \pm 0.05 vs $1.5 \pm 0.05, P<.01)$. Although the patients in the minimally invasive approach group had a better preoperative NYHA functional class, the net improvement in functional class was similar in the 2 groups $(1.01 \pm 0.74$ for sternotomy approach vs $0.85 \pm 0.61$ for minimally invasive approach, $P=.12$ ). Multivariable analysis revealed that only preoperative NYHA class (95\% confidence interval [CI], 0.006$0.362 ; P=.005)$ was significantly associated with NYHA class at follow-up.

Fig 3 depicts the cumulative survival from all valverelated complications (thromboembolic, anticoagulation, endocarditis, and reoperation for valve failure).
Table IV. Indications for mitral reoperation within the first postoperative year

\begin{tabular}{lcc}
\hline & $S S(n=100)$ & $M I(n=100)$ \\
\hline Endocarditis & 2 & 2 \\
Residual & 0 & 1 \\
Repair dehiscence & 2 & 0 \\
Progression of rheumatic disease & 0 & 1
\end{tabular}

$S S$, Standard sternotomy approach; $M I$, minimally invasive approach.

No differences were noted in the late complication rates between the 2 surgical approaches.

\section{Discussion}

These results demonstrate that a minimally invasive approach to mitral reconstruction can be accomplished with low perioperative risk while achieving the same intermediate-term results as the standard sternotomy approach. The lack of sternotomy, partial sternotomy, or rib osteotomies with the Port-Access minimally invasive approach avoids the complications associated with these bony incisions. Additional secondary benefits, such as decreased hospital stay, ${ }^{6}$ lower blood use, ${ }^{13}$ diminished patient discomfort, ${ }^{14}$ and enhanced recovery times, ${ }^{6,14,15}$ have been well documented previously. Similarly, other authors have reported excellent perioperative results for the minimally invasive approach for 


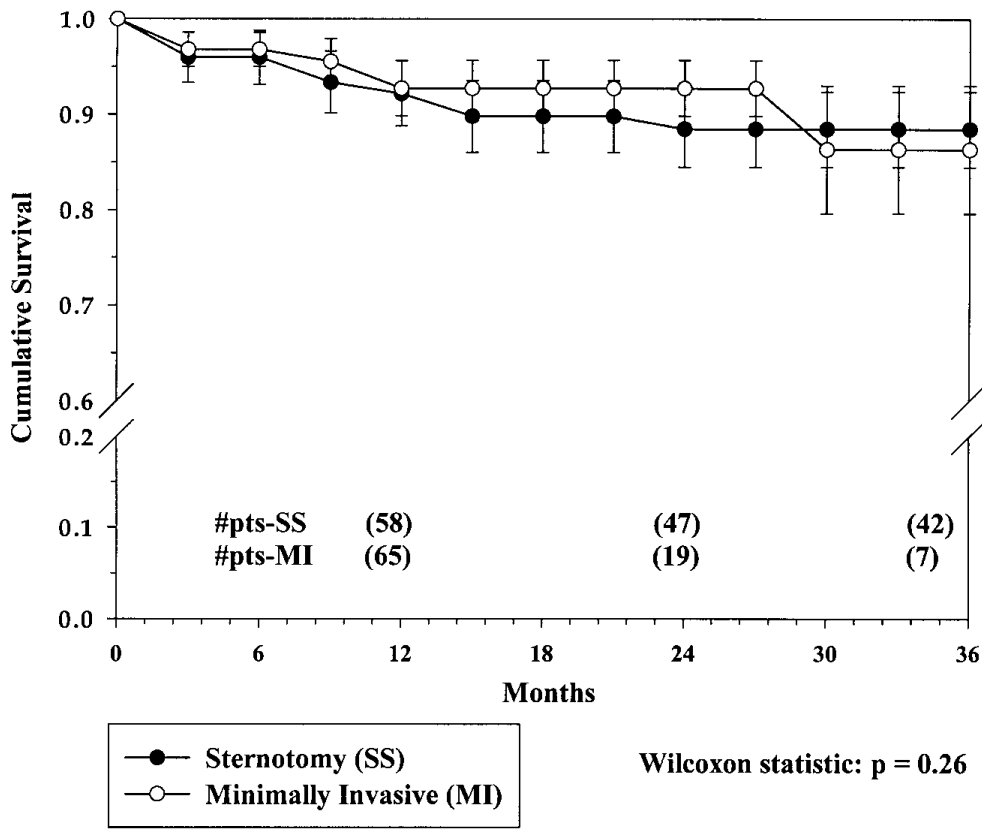

Fig 3. Cumulative survival from all valve-related complications (anticoagulant, endocarditis, and thromoembolic) and mitral reoperations. SS, Standard sternotomy approach; $M I$, minimally invasive approach.

mitral valve operations. ${ }^{4}$ Despite these early encouraging results, there have not been significant late followup reports after minimally invasive mitral valve reconstruction until now. This report demonstrates that the intermediate results of the minimally invasive approach for mitral reconstruction achieve patient improvement, repair durability, and echocardiographic results equal to those of median sternotomy.

It is noteworthy that the minimally invasive approach group patients were referred for the operation at an earlier symptomatic point in the course of their disease. All patients had severe insufficiency and either decreased ventricular function, decreased left ventricular stress performance, or symptoms. We can speculate that that the referral of patients with less NYHA functional impairment was due to either improved physician awareness for timing of intervention ${ }^{16,17}$ or a lowered threshold for surgical intervention, with a minimally invasive approach being available. Irrespective of the reasons for earlier intervention, this report confirms that earlier intervention results in better long-term patient functional status ${ }^{16,17}$ and improved ventricular function. This should ultimately translate into improved late survival.

It also should be noted that the minimally invasive approach group patients were a more consistent group with respect to the cause of valvular pathology, with
$92 \%$ of the patients having a degenerative cause compared with $72 \%$ in the 100 previous sternotomy approach group patients. This heterogeneity of cause will strengthen the power of long-term studies of the efficacy of the minimally invasive technique because this cohort is followed over multiple years.

During this initial experience with minimally invasive mitral valve repair, 11 patients underwent the standard sternotomy approach. This was due to the presence of either severe obstructive peripheral vascular disease or intraoperatively diagnosed atheromatous disease of the transverse arch and descending aorta. Such a low incidence of the sternotomy approach during this time period defines the bias of the surgeons performing this procedure: the minimally invasive approach was performed in all patients in whom concomitant vascular disease did not preclude its use. This bias is presumably the basis for the shift in patient demographics that occurred over time. Physicians referred patients earlier, with less-advanced ventricular damage for the less-invasive procedure, and patients actively sought our institution for this approach. Currently, a newer version of the aortic endovascular occluder has become available, which permits cannulation of the ascending aorta and antegrade perfusion. This technique now allows us to offer a minimally invasive approach to most patients in this subset. 
In summary, this study demonstrates that minimally invasive mitral valve repair results in comparable 1year echocardiographic results and similar net improvement in NYHA functional class when compared with patients undergoing the standard sternotomy approach. The minimally invasive approach for mitral valve repair is reproducible and durable and should be adopted more widely in view of the documented advantages of shorter postoperative recovery times and avoidance of chest wall skeletal trauma.

Received for publication May 16, 2000; revisions requested July 6, 2000; revisions received Oct 24, 2000; accepted for publication Oct 27, 2000.

Address for reprints: Eugene A. Grossi, MD, New York University Medical Center, Suite 9-V, 530 First Ave, New York, NY 10028 (E-mail: grossi@cv.med.nyu.edu).

\section{REFERENCES}

1. Gulielmos V, Wagner FM, Waetzig B, et al. Clinical experience with minimally invasive coronary artery and mitral valve surgery with the advantage of cardiopulmonary bypass and cardioplegic arrest using the port access technique. World J Surg 1999;23:480-5.

2. Gillinov AM, Cosgrove DM. Minimally invasive mitral valve surgery: mini-sternotomy with extended transseptal approach. Semin Thorac Cardiovasc Surg 1999;11:206-11.

3. Glower DD, Komtebedde J, Clements FM, Debruijn NP, Stafford-Smith M, Newman ME. Direct aortic cannulation for Port-Access mitral or coronary artery bypass grafting. Ann Thorac Surg 1999;68:1878-80.

4. Cohn LH, Adams DH, Couper GS, et al. Minimally invasive cardiac valve surgery improves patient satisfaction while reducing costs of cardiac valve replacement and repair. Ann Surg 1997;226:421-8.

5. Galloway AC, Shemin RJ, Glower DD, et al. First report of the PortAccess International Registry. Ann Thorac Surg 1999;67:51-8.
6. Glower DD, Landolfo KP, Clements F, et al. Mitral valve operation via port access versus median sternotomy. Eur $\mathrm{J}$ Cardiothorac Surg 1998;14(Suppl 1):S143-7.

7. Colvin SB, Galloway AC, Ribakove G, et al. Port-access mitral valve surgery: summary of results. J Card Surg 1998;13:286-9.

8. Grossi EA, Ribakove G, Schwartz DS, Galloway AC, Colvin SB. "Port access" approach for minimally invasive mitral valve surgery. Operative Techniques in Cardiac and Thoracic Surgery 1998;3:32-46.

9. Galloway AC, Colvin SB, Baumann FG, et al. Long-term results of mitral valve reconstruction with Carpentier techniques in 148 patients with mitral insufficiency. Circulation 1988;78(Suppl): I-97-105.

10. Spencer FC, Galloway AC, Grossi EA, et al. Recent developments and evolving techniques of mitral valve reconstruction. Ann Thorac Surg 1998;65:307-13.

11. Grunkemeier G, Jamieson WRE, Miller DC, Starr A. Actuarial versus actual risk of porcine structural valve deterioration. J Thorac Cardiovasc Surg 1994;108:709-18.

12. Grossi EA, Galloway AC, Miller JS, et al. Choice of mitral prosthesis in the elderly: an analysis of "actual" outcome. Circulation 1998;98(Suppl):II-116-9.

13. Grossi EA, Galloway A, Ribakove G, et al. Impact of minimally invasive approach on valvular heart surgery: a case controlled study. J Am Coll Cardiol 1999:554A.

14. Grossi EA, Zakow PK, Ribakove G, et al. Comparison of postoperative pain, stress response, and quality of life in port access vs. standard sternotomy coronary bypass patients. Eur J Cardiothorac Surg 1999;16(Suppl 2):S39-42.

15. Grossi EA, Galloway AC, Ribakove GH, et al. Impact of minimally invasive approach on valvular heart surgery: a case controlled study. Ann Thorac Surg 2000. In press.

16. Ling LH, Enriquez-Sarano M, Seward JB, et al. Early surgery in patients with mitral regurgitation due to flail leaflets: a long-term outcome study. Circulation 1997;96:1819-25.

17. Enriquez-Sarano M, Orszulak TA, Schaff HV, Abel MD, Tajik AJ, Frye RL. Mitral regurgitation: a new clinical perspective. Mayo Clin Proc 1997;72:1034-43. 